\title{
An investigation into HSE educational programs in the USA
}

\author{
M. Albuti ${ }^{1}$ \& G. Reniers ${ }^{1,2,3}$ \\ ${ }^{1}$ Research Group ARGOSS, Faculty of Applied Economic Sciences, \\ University of Antwerp, Belgium \\ ${ }^{2}$ Safety and Security Science Group, Faculty of Technology, Policy, \\ and Management, Delft University of Technology, The Netherlands \\ ${ }^{3}$ Faculty of Economics and Management, Campus Brussels, Belgium
}

\begin{abstract}
As the demand for safety professionals in industry is ever more increasing, companies are becoming keener on having candidates that have precise knowledge in HSE management and its elements. The knowledge, much desired by companies, is neither technical nor managerial but a balance of both. A handful of universities in the United States have created 'Safety' programs that acquire program graduates the knowledge needed for industry. The 'Safety' educational programs are somewhat new compared to most programs offered in universities. The educational programs investigated in this study are accredited by national and international educational boards. Those educational boards require those programs to be continually improved to ensure students are attaining the objectives and goals set for the programs. Our investigation shows in what way the 'HSE' needs of industry are met in the 'Safety' educational programs that are offered in the United States. The reporting prevails gaps that were found, similarities and differences in programs, interpretation of the findings, and finally recommendations.

Keywords: safety education, HSE education, HSE management, safety management, PDCA, hazard identification, operational control, risk assessment, training for safety and health, crisis management and disaster preparedness.
\end{abstract}




\section{Introduction}

Regular students (not coming from the industry) graduating from HSE programs in the USA need to have well rounded knowledge regarding HSE (Health, Safety, Environment) and the accompanying models and systems. HSE educational programs are indeed designed to cover certain key HSE elements that are useful in industry. Our study investigates these HSE key elements, with their applicability within the industry in mind. As this field is rather new and educational programs are under continuous improvement, this investigation will identify the similarities and differences between programs and what are believed to be shortcomings when assessed from the industrial perspective. Students starting a job and joining the workforce in an industrial sector, sometimes seem to be lacking in a certain element of HSE. Although academic institutions provide the most important generic elements required for HSE management systems, those HSE elements that graduates often seem to be lacking, are those elements that are implemented and operated differently in each company.

Educational programs need to satisfy the needs of certain goals and objectives. The method to identifying the goals of such educational programs is the result of several cycles of analysis and improvement. The Accreditation Board for Engineering and Technology (ABET, 2015) [1], puts it this way: "The program must regularly use appropriate, documented processes for assessing and evaluating the extent to which the student outcomes are being attained. The results of these evaluations must be systematically utilized as input for the continuous improvement of the program. Other available information may also be used to assist in the continuous improvement of the program."

In the remainder of this paper, an overview of the HSE elements that HSE departments in the industry operate and live by, is first drafted and looked at. Second we investigated if educational programs are covering those elements that are adopted in HSE departments in industry.

\section{Methodology}

The selection criteria for determining the programs to be analyzed in our study, were the following. Programs can, and do, often have different names but having similar goal(s) and are also characterized by a different level of contents depth. A program could be called 'safety management' in one institute and 'Occupational Safety and Health' in another institute, but could have similar program goals and objectives, and they will both be considered. However, the programs should be under the same category for accreditation, which is 'Safety'. They should not be purely technical or managerial, but a mix. Furthermore, the programs considered are of a bachelors' level and if the academic institute did not offer this bachelors' option, then the Masters' level was chosen.

After finding $50 \mathrm{HSE}$ educational programs within the United States (CHEA Database) [2], only 13 passed the selection criteria for HSE management programs explained above. Most of the programs are strictly technical engineering programs, and therefore did not fit the criteria. Although 17 
programs are accredited as "Safety" programs by the Council for Higher Education Accreditation in the United States, 4 of the 17 programs did not pass because they are safety programs but they either have one highly specific focus, such as radiation protection, emergency management, or because they are not the level of degree we are investigating ('associate degree'). Out of the 13 programs, 9 are ABET certified programs [3]. ABET [4] mentions that "Accreditation provides an opportunity for academic institutions to demonstrate they are committed to maintaining their programs' quality and that their programs are performing at the level required by the professions they serve. Programs undergo periodic accreditation to ensure that they continue to meet quality standards set by the profession. The result provides lasting benefits to students, the institution, employers, the professions, and society as a whole."

The study included all possible 'core electives', which are non-obligatory courses offered in the educational program. Since the required courses are not enough to complete the study program, students are obligated to complete a few electives of their choice from a designated list that is set by the faculty. Some programs offer more core electives than others.

\section{Research results}

HSE departments in the industry develop, follow and implement management systems. Those management systems could be adopted from one or more generic management systems that are tweaked and modified for the needs of the company. Lyons and Plisga [5] have stated "One of the key recommendations was that companies should have safety management systems that control a company's operations from top to bottom. The systems were recommended to include the elements of ISO 9001 (a standard for management of quality in organizations)."They all have one common item which is the use of the cycle of continuous improvement. The continuous improvement cycle is also known as the plan-do-check-act (PDCA) cycle. As Maruta [6] refers to Imai's words, "The PDCA cycle was initially employed as a tool for product quality control, and then it was recognized as a tool for production process improvement." Mukherjee [7] also describes it in a highly manner by stating "The PDCA cycle keeps on rectifying the errors and assures that they do not repeat again and again. This ensures that the PDCA cycle puts an organization on the path of continues improvement." It is obvious that the first key element of any HSE educational program should be to become acquainted with the use of different management systems and with the PDCA cycle.

'Planning' is the first phase of the PDCA loop. In relation to the Planning phase, an educational program may include courses that cover elements of policy, hazard identification and risk assessment. Planning also includes knowledge about, and familiarization of, legal and other requirements, such as industry standards, which are also key elements of adequate HSE within the chemical industry. The 'Do' phase should, amongst others, include structures and responsibilities, safety training, awareness, and communication. Document and data control, operational control, and emergency preparedness and -response 
including crisis management, is also part of the 'Do' phase within the PDCA loop. The 'Check' phase includes elements such as inspection, auditing, testing incident reporting and verifying the corrective/preventive actions and measures that have been taken in the previous phase. The 'Act' phase from the continuous improvement cycle includes analysis of what is being reported and taking actions upon it.

Courses related to the PDCA loop are important for HSE educational programs, since they form the basis for effective management systems within organizations in the industry. Table 1 provides coverage of learning elements found within the investigated/selected educational programs. The table shows the number of universities that offer HSE programs completely covering the element related to the PDCA loop. This table for example shows that 12 of the 13 selected HSE educational programs cover the element of 'management systems', and all programs cover the element of 'hazard identification and risk assessment' and 'operational control'. 'Legal' is not covered by one of the HSE educational programs. 'Incident investigation/corrective and preventive action' is an element that is fully covered by 11 of the programs investigated. Surprisingly maybe, only about half of the programs cover the elements of 'safety and health training' and 'emergency preparedness/crisis management'.

Table 1: Number of universities/educational programs that cover the PDCA element.

\begin{tabular}{|l|c|}
\hline Element & $\begin{array}{c}\text { Number of programs covering the } \\
\text { element }\end{array}$ \\
\hline management systems & $12 / 13$ \\
\hline hazard identification/risk assessment & $13 / 13$ \\
\hline legal and other requirements & $12 / 13$ \\
\hline operational control & $13 / 13$ \\
\hline training for safety and health & $8 / 13$ \\
\hline $\begin{array}{l}\text { emergency preparedness/crisis } \\
\text { management }\end{array}$ & $6 / 13$ \\
\hline $\begin{array}{l}\text { incident investigation/corrective and } \\
\text { preventive action communication, }\end{array}$ & $11 / 13$ \\
\hline $\begin{array}{l}\text { Other (e.g., } \\
\text { document control, etc.) }\end{array}$ & $8 / 13$ \\
\hline
\end{tabular}

From Table 1 it can be observed that not all programs cover all elements. Figure 1 further displays the numbers obtained when dividing the number of courses by the number of programs that are offering the PDCA element. This way, it is possible to have an idea of the level of contents' depth of an element in the educational programs. For example, on average there are 4.85 classes that cover the element of 'operational control' in an educational program. Hazard identification/risk Assessment has an average of 3.08 courses per educational program, 'management systems' 2.33 courses. 


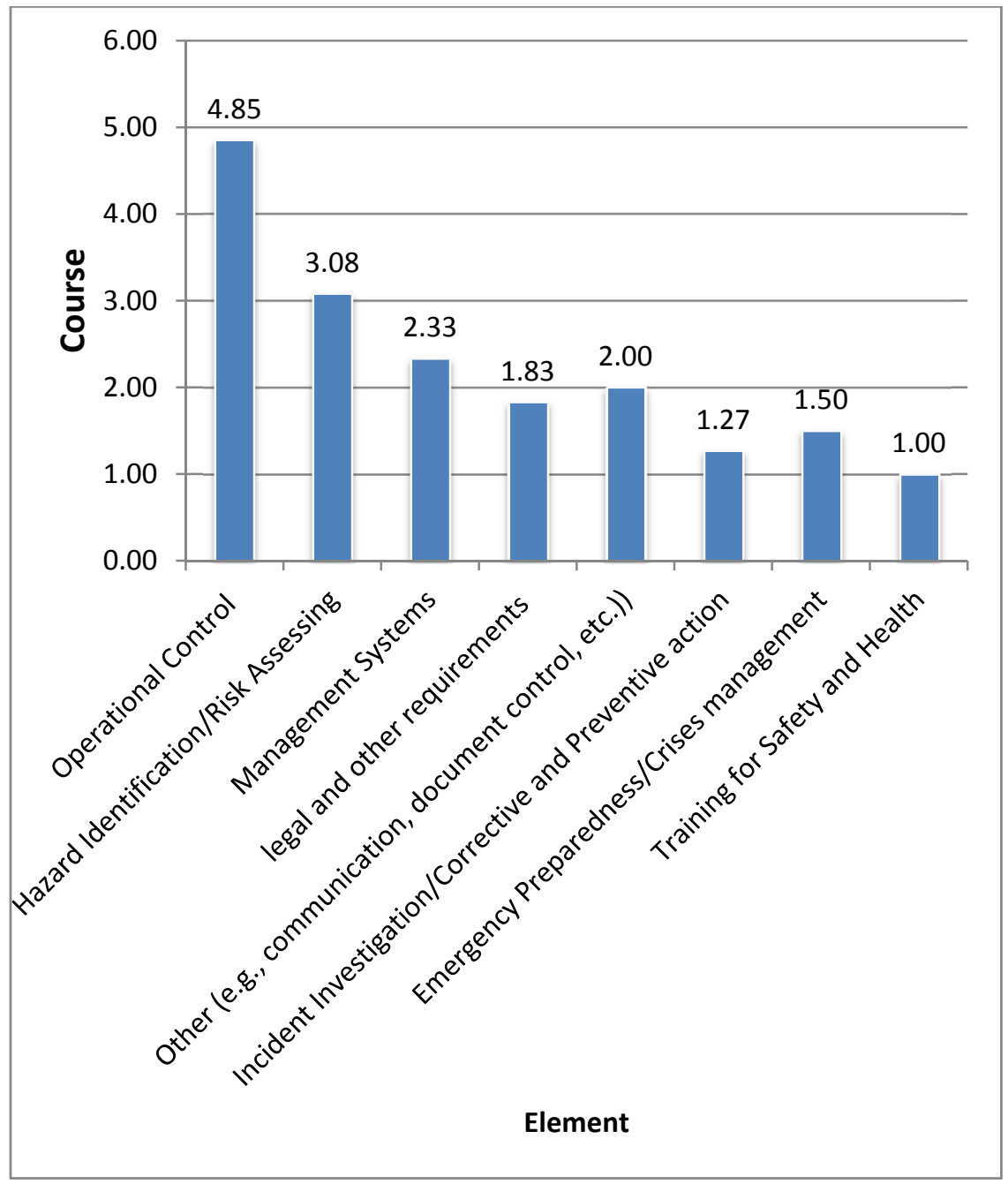

Figure 1: Average number of courses covering each element.

A university has several 'colleges', depending on its size, how much staff it has, its facilities, and its funding. A university could thus have separate colleges for engineering and for technology, but it also could have one college for engineering, science, and technology all at once. Our study indicated that HSE educational programs were offered and accredited in one of the following colleges: 'engineering', 'science', 'health', or 'technology'. In order for the program to be accredited it must have full time faculty members dedicated to the program, with one faculty member being the program administrator in charge. 


\section{Conclusions}

This study identifies and investigates HSE educational programs in the United States. Going through curricula and programs, most have been identified as technical HSE programs that did not qualify for our investigation. We found that HSE educational programs in the USA have a clear trend of including courses on 'operational control' and on 'hazard identification / risk assessment'. This trend shows the focus on the engineering and technical elements. Since all programs are in an engineering, technology, health, or science college, it logically contains very technical faculty, and therefore the focus would evidently be on technical elements.

Elements such as 'safety training' and 'emergency preparedness and crisis management' are not always included in courses within the program, which represents a shortcoming of the current situation. A course in 'safety training' requires less technical and more managerial teachings, and hence, faculty members would need extensive background in training how to train. This also includes 'emergency preparedness and crisis management', where faculty must be very specialized in order to teach and fully explain the technicalities of this element. Companies do include these elements in their HSE management system, therefore all programs investigated should have these elements integrated in them because they are elements that could be taught and would not vastly differ from organization to the other.

Based on the findings of our study, we may conclude that an expert who is very knowledgeable in operational control and hazard identification is much easier to find than someone who can flawlessly create and manage HSE training programs or who has the specified expertise to create and maintain a crisis management program. Consultants with specific experience are therefore paid to help organizations around the globe to maintain those two elements. It can thus be recommended to put more emphasis on safety training and on crisis management in available and accredited HSE educational programs in the USA.

Future research includes a similar analysis of educational programs within the UK and also continental Europe. Furthermore, other topics such as cybersecurity can be considered to be investigated, as well as a comparison between European programs and US programs.

\section{References}

[1] Accreditation Board of Engineering and Technology (ABET). Criteria for Accrediting Applied Science Programs, 20015-2016. http://www.abet.org /asac-criteria-2015-2016

[2] CHEA Database of Programs Accredited By Recognized U.S. Accrediting Organizations. CHEA Database of Programs Accredited By Recognized U.S. Accrediting Organizations. http://www.chea.org/search/actionProg.asp

[3] Accreditation Board of Engineering and Technology (ABET). Find Accredited Programs. http://main.abet.org/aps/AccreditedProgram Search.aspx/AccreditationSearch.aspx 
[4] Accreditation Board of Engineering and Technology (ABET). Why Accreditation Matters to Programs and Institutions. http://www.abet.org /accreditation-matters-programs-institutions

[5] Lyons, W.C. \& Plisga G.J, (eds). Standard Handbook of Petroleum \& Natural Gas Engineering, Elsevier Inc., Oxford, 2005.

[6] Maruta, R., Maximizing Knowledge Work Productivity: A Time Constrained and Activity Visualized PDCA Cycle. Knowledge and Process Management, 19(4), pp. 203-214, 2012.

[7] Mukherjee, P.N., Prentice-Hall of India, Private Limited., Total Quality Management, New Delhi-110001, p. 234, 2006. 